\title{
Bacterias y hongos en el humo aspirado de cigarrillo
}

\section{Bacteria and fungi in cigarette smoke}

\author{
José Olivo Lopez ${ }^{1}$, Jhimer Capcha Sánchez², John Chávez Salazar³
}

${ }^{1}$ Instituto de Salud del Niño, Universidad Nacional Federico Villarreal, Universidad Norbert Wiener, Lima, Perú jolivo@insn.gob.pe

Universidad Nacional Federico Villarreal, Asoc. Las flores Mz. A LT. 6, Santa Anita, Lima, Perú jcapchasanchez@gmail.com

3Universidad Nacional Federico Villarreal, Distrito del Rímac, Lima Perú johnjc.chavez@gmail.com

Recibido el 11 de noviembre del 2016; aceptado el 15 de diciembre del 2016

DOI: https://doi.org/10.33017/RevECIPeru2016.0010/

\section{Resumen}

Estudios confirman la presencia de microorganismos potencialmente patógenos en la hoja de tabaco. Estos podrían llegar por arrastre a través del humo a las vías respiratorias y desencadenar una serie de enfermedades pulmonares. Por lo tanto, los cigarrillos podrían considerarse una fuente directa de microorganismos que llegarían a colonizar el tracto respiratorio de fumadores activos, especialmente en inmunodeprimidos. El objetivo fue determinar si las bacterias y hongos presentes en la hoja de tabaco son arrastrados al aspirar el humo de cigarrillos. Estudio transversal y prospectivo de diseño no experimental. Se realizó en el agustino en la que se procesó 10 cajetillas de cigarrillos de dos marcas diferentes (dos grupos de 5 cajetillas) utilizando un sistema de aspiración mecánica que consta de un matraz de kitazato, pipeta graduada, jeringa de $60 \mathrm{ml}$, conductos y tapones de jebe. De 10 cajetillas analizadas de la marca A (5 cajetillas), se obtuvo crecimiento bacteriano en el $80 \%$ y en la marca B(5 cajetillas), un $60 \%$ ambas correspondientes a Bacillus sp. No se aisló mohos y levaduras. Se concluye que bacterias presentes en la hoja de tabaco son arrastrados a través del humo de cigarrillo.

Descriptores: Hoja de tabaco, humo aspirado, Bacillus sp, inmunodeprimidos.

\section{Abstract}

Summary: Studies confirm the presence of potentially pathogenic microorganisms in leaf snuff. These could be reached by drag through the smoke to the airways and trigger a number of lung diseases. Therefore, the cigarettes could be considered a direct source of microorganisms that come to colonize the respiratory tract of active smokers, especially in immunosuppressed. The objective was to determine if bacteria and fungi in leaf snuff are drawn by aspirating smoke cigarettes. transversal and prospective study of non-experimental design. It was held in the Augustinian where 10 cigarette packets of two different brands (two groups of 5 packs) using a mechanical suction consisting of a flask Kitazato, graduated pipette, syringe $60 \mathrm{ml}$, ducts and caps processed jebe. 10 packs analyzed brand A (5 packs), bacterial growth was obtained in $80 \%$ and the mark $\mathrm{B}$ (5 packs), 60\% both corresponding to Bacillus sp. No molds and yeasts isolated. It is concluded that bacteria present in the leaf snuff are drawn through the cigarette smoke.

Keywords: Leaf snuff, inhaled smoke, Bacillus sp, immunosuppressed. 


\section{Introducción}

El tabaquismo es un problema social y de salud pública, reconocido como un factor de riesgo para una amplia gama de enfermedades respiratorias en niños y adultos, incluyendo el resfriado común, la gripe, el asma, la neumonía bacteriana, y la enfermedad pulmonar intersticial [1,2]. Según la Organización Mundial de la Salud (OMS) la mortalidad es de 6 millones de personas al año, de las cuales más de 5 millones son consumidores directos y más de 600000 son no fumadores expuestos al humo ajeno [3]. Los fumadores muestran mayor colonización bacteriana sublingual que los no fumadores, el cual guarda relación directa con el número de cigarrillos consumidos/día, de tal manera que los fumadores de menos de 10 cigarrillos/día presentan entre 2,56 veces más periodontitis que los no fumadores [4]. Además, el tabaquismo está asociado a un aumento significativo del riesgo de neumonía, enfermedad neumocócica invasiva e infección por legionella spp. [5,6]. Asimismo uno de los problemas que se ha visto en los fumadores crónicos es el desarrollo de Candidiasis Oral, ya que dicho hábito conlleva a alteraciones epiteliales que facilitan la colonización por esta levadura [7].

Fumar cigarrillo es la principal causa de cáncer de pulmón [IARC 2004] y el factor de riesgo principal para la enfermedad pulmonar obstructiva crónica. Además, el tabaquismo es cada vez más reconocido como un factor de riesgo para una amplia gama de otras enfermedades respiratorias en niños y adultos, incluyendo el resfriado común, la gripe, el asma, la neumonía bacteriana, y la enfermedad pulmonar intersticial, para nombrar unos pocos [8]. Muchos estudios han evaluado los productos químicos, tóxicos y elementos carcinógenos en el humo de tabaco [9, 10,11]. En 1985, los diferentes grupos de trabajo se reunieron para identificarlos productos químicos en el humo del tabaco que tienen más probabilidades de ser cancerígeno para los seres humanos según los criterios de la Asociación Internacional para la Investigación sobre el Cáncer (IARC), un organismo intergubernamental que forma parte de la Organización Mundial de la Salud, y por el Programa de Estados Unidos Nacional de Toxicología (NTP) $[9,10,11]$. Hoy en día, se sabe que el humo de cigarrillo se compone de al menos 5.300 productos químicos diferentes [11].

En cuanto a los elementos microbianas asociados al tabaco se incluyen bacterias (Gram positivas y Gram negativas), esporas bacterianas, hongos (levaduras y mohos), esporas de hongos, componentes de la pared celular (ciertos glucanos y flagelo), y diversas toxinas microbianas que incluyen exotoxinas y endotoxinas. Ejemplos de toxinas derivadas de bacterias incluyen endotoxinas (lipopolisacárido, LPS; factor inflamatorio) y micotoxinas derivados de hongos (aflatoxinas, AFde tipoB1; carcinógeno humano) $[9,10,11]$.

Un estudio reciente de la metagenómica bacteriana de cigarrillos, en la que se utilizó un micro-ensayo de taxonomía por rRNA16S, métodos de clonación y secuenciación tradicionales, se identificaron quince clases de bacterias; destacándose a Klebsiella, Bacillus, burkholderia, Closteridium, Actinetobacter, Pseudomonas aerogenosa, y Serratia. Otras bacterias que se sabe que son potencialmente patógenas para los seres humanos y detectado usando la tecnología metagenomica eran Campylobacter, Enterococcus, Proteus, Staphylococcus [11].

Otras investigaciones también han identificado bacterias patógenas en los cigarrillos comerciales $[12,13]$.Identificaron ocho especies de Bacillus en los cigarrillos recogidas de personal militar durante una investigación de neumonitis eosinofílica aguda entre los individuos que habían sido desplegados durante la Operación Libertad Iraquí [13]. En otro estudio recuperaron Bacillus spp., incluyendo Bacillussubtilis, de las hojas de tabaco frescas recogidas en un tabaco de fabricación de la planta. Bacillus spp [14]. Papavassiliou et.al. (1971) llegaron a la conclusión de que los cigarrillos están contaminados con diversos hongos." Estudiaron los cigarrillos que fueron fabricados en los EE.UU., Canadá, Inglaterra, Francia, Bélgica, Alemania, Jordania y Egipto. Se aislaron cientos de cepas de hongos. El hongo que se aíslo con mayor frecuencia fue Aspergillus (28 cepas de cigarrillos griegos y35cepasde otros países). Ellos relacionan a los hongos con las alergias, pero comentaron que este problema no se ha resuelto [15].

Estudios recientes demostraron que, en el humo de tabaco, el ácido murámico, un marcador de peptidoglicano que puede servir como un indicador de bacterias gram-positivas, se encuentran en niveles elevados [16]. Por todo lo expuesto anteriormente, los microorganismos presentes en 
las hojas de tabaco podrían considerarse un factor de riesgo importante que llegaría por arrastre, a través del humo, al tracto respiratorio y provocar una serie

de enfermedades pulmonares sobre todo en personas inmunodeprimidas.

El objetivo fue determinar si las bacterias y hongos presentes en la hoja de tabaco son arrastrados al aspirar el humo de cigarrillos.

\section{Metodología}

Se realizó un estudio transversal y prospectivo de diseño no experimental, se utilizó dos marcas distintas de cigarrillos adquiridos en el agustino entre los meses de marzo y julio, estos fueron sometidos a un proceso de aspiración mecánica este sistema estuvo constituido por un Matraz de Kitazato $(100 \mathrm{ml})$, pipeta volumétrica $(5 \mathrm{ml})$, jeringa $(60 \mathrm{ml})$, conducto y tapón de jebe (todos estériles).

Los medios de cultivos y colorantes utilizados fueron: Caldo nutritivo, agar MacConkey, TSA, Agar sangre, agar almidón y medios diferenciales para Gram negativos (citrato de Simmons, TSI, LIA, SIM) y Agar Saboraud; Peróxido de hidrogeno, reactivo de oxidasa; coloración verde de Malaquita, coloración Gram y azul de Lactofenol.

\section{3. procedimiento}

\subsection{Preparación del sistema:}

Se conectó un extremo del conducto de jebe de $10 \mathrm{~cm} \times 8 \mathrm{~mm}$ en la punta de la jeringa y en el otro extremo la parte superior de la pipeta volumétrica. Introduciéndose el extremo inferior de pipeta estéril en el agujero del tapón de jebe y éste en la boca del matraz de kitazato. Se conectó el conducto de jebe de $3 \mathrm{cmx} 8 \mathrm{~mm}$ en el pico del matraz de kitazato, y en el extremo libre del mismo se colocó la boquilla del cigarrillo hasta que el conducto cubra el filtro.

\subsection{Aspiración del humo:}

Una vez elaborado el sistema se encendió el cigarrillo jalando el émbolo de la jeringa con lo que se logró concentrar la cantidad suficiente de humo en el interior del matraz; lo que permitió que el cigarrillo se consuma en su totalidad. Luego, se procedió a quitar el filtro restante colocando un trozo de algodón en el pico del matraz (para proteger el cultivo de la contaminación), de la misma manera se quitó el tapón de jebe e introducir un pedazo de algodón en la boca del matraz. Finalmente se incubo el matraz en la estufa a $37^{\circ} \mathrm{C} \times 24 \mathrm{~h}$.

\subsection{Aislamiento:}

Después del tiempo de incubación se observó la turbidez en el medio de cultivo y con un asa se resembro a las placas de agar tripticasa de soya (TSA), Agar MacConkey, Agar almidón, Agar sangre para luego incubamos las placas a $37^{\circ} \mathrm{C} x$ 24h. Igualmente, se sembró en Agar saboraud y éste se incubo a To ambiente durante 72 horas.

Desde el cultivo obtenido en el matraz se realizó las coloraciones de verde malaquita y Gram Finalizada las coloraciones de las láminas, se observó en el microscopio con el objetivo de 40x e inmersión. Igualmente, desde las colonias obtenidas en el TSA, Agar Manitol Salado, se realizó la coloración Gram; y coloración de Verde Malaquita a partir de las colonias del TSA.

\section{Resultados y discusión}

\subsection{Resultados:}

Los datos obtenidos revelaron la detección de bacillus sp. en el humo aspirado de cigarro (tabla1). De 10 cajetillas analizadas correspondientes a la marca A (5 cajetillas), se obtuvo crecimiento bacteriano en el $80 \%$, en la coloración Gram realizada a partir de las colonias del TSA, agar almidón y agar sangre se observaron Bacilos gram positivos con algunas variaciones en su morfología bacilar, en las coloraciones de Verde Malaquita realizadas a partir de las colonias del TSA se observaron esporas bacterianas de color verde sobre un fondo azul, y en la marca $\mathrm{B}(5$ cajetillas $)$ el crecimiento bacteriano fue del $60 \%$, observándose en las coloraciones Gram y verde malaquita estructuras similares a la anterior. No se apreció crecimiento alguno en los agares saburaud vale decir, no se aisló mohos y levaduras.

\subsection{Discusión:}

Exploramos el humo aspirado de cigarrillos, siendo bacillus sp la bacteria aislada en gran parte de los 
cigarrillos analizados. Con el sistema de aspiración que hemos elaborado se logró concentrar la mayor cantidad de humo; permitiendo de esta manera, el desarrollo óptimo de los agentes en el medio líquido de cultivo.

Con respecto al humo de cigarrillo, la microbiología de esta compleja mezcla todavía no ha sido estudiada detalladamente. Hasta la actualidad, la mayoría de los estudios microbiológicos sobre los

componentes del humo del cigarrillo se han centrado en endotoxinas (Barnes y Glantz 2007 [17]; Hasday et al., 1999 [18]; Larsson et al., 2004 [19]; Reiman y Uitti 2000 [20]; Rennie et al., 2008 [21]; Sebastián et al., 2006 [22]; Thorne et al. 2009) [23]. Hasday et al (1999) demostró por primera vez que el humo principal y secundario contienen niveles significativos de endotoxina bacteriana. Además de las endotoxinas presentes en el humo de tabaco [18], Larsson et al (2008) demostró que los niveles elevados de ácido murámico, un marcador de peptidoglicano, puede servir como un indicador de bacterias Gram positivas [19]. Sin embargo, más allá de estos marcadores bacterianos, muy poco trabajo se ha realizado para evaluar las células bacterianas viables en el humo aspirado. Con este estudió demostramos que las bacterias presentes en la hoja de tabaco logran atravesar el filtro de los cigarrillos al aspirar el humo y sería interesante demostrar en investigaciones futuras que las bacterias que logran atravesar el filtro podrían colonizar de alguna forma el tracto respiratorio en fumadores activos sobre todo en inmunodeprimidos.

\section{Conclusiones}

En el presente trabajo se concluye que bacterias presentes en la hoja de tabaco son arrastrados a través del humo de cigarrillo.

\section{Agradecimientos}

El presente trabajo se realizó gracias a los

Profesores de microbiología de la Universidad Nacional Federico Villareal a quienes expresamos nuestro agradecimiento.

\section{Referencias}

[1] S. Murin, K.S. Bilello, R. Matthay. Other smoking-affected pulmonary diseases. Clin Chest Med vol. 21, pp.121-137, 2000.
[2] D.M. Mannino, A.S. Buist. Global burden of COPD: risk factors, prevalence, and future trends. Lancet vol.370 pp.765-773, 2007.

[3] Organización Mundial De La Salud (OMS),2016

http://www.who.int/topics/tobacco/es/

[4] S.L. Tomar. Asma Smoking-attributable periodontitis in the United States: Findings from NHANES III: Nacional Health and Nutrition Examination SurveyJ Periodontololgy, vol. 71 pp.743-751, 2000.

[5] A.J. Raman, A.Q.J. Swinburne. Fedullo Pneumococcal adherente to the bucal epithelial cells of cigarette smokers Chest, vol. 83 pp. 23-27, 1983

[6] J. M. Roig, M.L. Sabrià, Pedro-Botet Legionell spp.: Community acquired and nosocomial infections Curr Opin Infect Dis, vol.16, pp.145-151, 2003

[7] N.S. Soysa, A.N.B. Ellepola. The impact of cigarette/tobacco smoking on oral candidosis: an overview. Oral Dis; vol.11, pp. 268-73, 2005.

[8] M. Borgerding and $\mathrm{H}$. Klus, "Analysis of complex mixtucigarette smoke," Experimental Toxicology and Pathology. Vol.57, pp. 43-73, 2005.

[9] R. R. Baker, "Smoke chemistry," in TOBACCO: ProChemistry and Technology, D. Lay, S.S. Hecht. "Cigarette smoking: cancer risks, carcinogen and mechanisms", Langenbeck's Archives of Surgery, vol. 6, pp. 603-613, 2006.

[10] D. Ten and M. T. Neds, Blackwell Science, chapter 12, 398-439, 2003.

[11] A.R. Sapkota, S. Berger, and T. M. Vogel, "Human pathogens abundant in the bacterial metagenome of cigarettes," Environmental Health Perspectives, vol. 118, no. 3, pp. 351356, 2010.

[12] J. Yang, J. Duan, et al., "Bacterial diversities on unaged and aging flue-cured tobacco leaves estimated by 16SrRNAsequenceanalysis," Applied

Microbiology and Biotechnology, vol. 88, pp. 553-562, 2010.

[13] A.P. Rooney, J.L. Swezey, D.T. Wicklow, M.J. McAtee. Bacterial species diversity in cigarettes linked to an investigation severe pneumonitis in U.S. military personnel deployed in Operation Iraqi Freedom. Current Microbiology. vol.51, pp.46-52. 2005.

[14] L. Larsson, B. Szponar, B. Ridha, C. Pehrson, J. Dutkiewicz, E. KrysinskaTraczyk, et al. 2008. Identification of bacterial and fungal components in tobacco and 
tobacco smoke.Toblnduc Dis 4:4.;doi: 10.1186/1617-9625-4-4

[15] J. Papavassiliou, G. Piperakis, and U.Marcelou-Kinti,"Mycological flora of cigarettes," Mycopathology Mycology Applied, vol. 44, no. 2, pp. 117-120, 1971.

[16] L. larsson, Microbiological components in mainstream and sidestream cigarette smoke, biomed central 10 (1), DOI: 10.1186/16179625-10-13 2012.

[17] R.L. Barnes, S.A. Glantz. Endotoxins in tobacco smoke: shifting tobacco industry positions. Nicotine Tob Res 9:995-1004, 2007.

[18] J.D. Hasday, R. Bascom, J.J. Costa, T. Fitzgerald, W. Dubin. Bacterial endotoxin is an active component of cigarette smoke. Chest vol.115 pp.829-835, 1999.

[19] L. Larsson, B. Szponar, C.Pehrson. Tobacco smoking increases dramatically air concentrations of endotoxin. Indoor Air, vol.14 pp.421-424. 2004.
[20] M. Reiman, J. Uitti. Exposure to microbes, endotoxins and total dust in cigarette and cigar manufacturing: an evaluation of health hazards. Ann Occup Hyg 44:467-473, 2000.

[21] D.C. Rennie, J.A. Lawson, S.P. Kirychuk, C. Paterson, P.J. Willson, A. Senthilselvan, et al. Assessment of endotoxin levels in the home and current asthma and wheeze in school-age children. Indoor Air. vol.18, pp.447-453, 2008.

[22] A. Sebastian, C. Pehrson, L. Larsson. Elevated concentrations of endotoxin in indoor air due to cigarette smoking. J Environ Monit 8:519-522, 2006.

[23] P.S. Thorne, R.D. Cohn, D. Mav, S.J. Arbes, D.C. Zeldin.. Predictors of endotoxin levels in U.S. housing. Environ Health Perspect. vol.117 pp.763-771. 2009. 